\title{
ARTÍCULO
}

\section{Los derechos humanos en la sociedad del riesgo. Crisis del Estado, justicia intergeneracional y medio ambiente}

\section{Human rights in risk society. State crisis, intergenerational justice and environment}

\author{
Alfonso de Julios-Campuzano \\ Departamento de Filosofía del Derecho \\ Universidad de Sevilla
}

Fecha de recepción 25/09/2017 | De aceptación: 06/06/2018 | De publicación: 27/06/2018

\section{RESUMEN.}

Esta era de la globalización es la era del riesgo global (Beck), que se caracteriza por el creciente nivel de riesgo en el manejo de los medios técnicos. En ese contexto, resulta cada vez más notoria la insuficiencia de un modelo de comprensión de los derechos humanos vinculado a la primera Modernidad. Frente a ello, reivindicamos un nuevo paradigma de los derechos humanos que, a partir de la dimensión global de los problemas y de una concepción intergeneracional de la justicia, trascienda los límites territoriales del Estado e incorpore la dimensión del futuro en la protección de los bienes jurídicos.

\section{PALABRAS CLAVE.}

Sociedad del riesgo, derechos humanos, nuevas tecnologías, globalización, medio ambiente, justicia intergeneracional

\section{ABSTRACT.}

The globalisation era is, as Beck has pointed out, the age of global risk, characterized by the increasing level of risk in the management of technical means. In this context, the insufficiency of a model of understanding human rights linked to the first modernity becomes increasingly evident. Against this, we demand a new paradigm of human rights that, from the global dimension of problems and from an intergenerational conception of justice, transcend the territorial limits of the State and incorporate the dimension of future in the protection of legal assets.

\section{KEY WORDS.}

Risk society, human rights, new technologies, globalization, environment, intergenerational justice

\footnotetext{
- Este trabajo ha sido producido en el seno del proyecto de excelencia "Fundamentos teóricos del neoconstitucionalismo: un modelo jurídico para una sociedad global" (DER2016-76392-P), del Programa Estatal de Fomento de la Investigación Científica y Técnica de Excelencia, (Ministerio de Economía y Competitividad), del que es investigador principal el autor del artículo.
} 
Sumario: 1. Producción normativa y seguridad jurídica en un contexto global; 2. La gestión del riesgo en la era de la globalización; 3. La protección de los derechos en la sociedad del riesgo; 4. La universalización de los derechos humanos y la justicia intergeneracional; 5. Un nuevo paradigma de los derechos humanos

\section{Producción normativa y seguridad jurídica en un contexto global}

Las nuevas formas del capitalismo maduro, aceleradas en las coordenadas de la globalización, y la creciente complejidad de los procesos sociales y políticos, unidas a los avances científicos, la revolución informática y la propia insuficiencia de la estructura estatal ante procesos de integración que se anuncian irreversibles han contribuido a crear un ambiente de crisis en torno al proyecto de la Modernidad y al sistema jurídico abstracto y universal sobre el que éste se asentó; crisis que es preconizada desde distintos sectores del pensamiento y que, abundando en las raíces teóricas de la Modernidad, insisten en poner de relieve la insuficiencia, cuando no directamente la inviabilidad, del proyecto moderno y del sistema jurídico que éste vino a propiciar.

Esta conciencia de crisis se ha visto particularmente favorecida por el desbordamiento de los modelos tradicionales ante los vertiginosos avances tecnológicos y las mutaciones que éstos han provocado en la dinámica económica, social y política de un mundo cada vez más interdependiente.

La crisis de la Modernidad augura el inicio de una nueva era: la de la interdependencia y la globalización, la de la disolución de las fronteras y la conformación de nuevas formas sociales y políticas, la de la ruptura de los esquemas unitarios del saber y el cuestionamiento de las verdades consolidadas...

El viejo modelo de la razón ilustrada parece resquebrajarse ante la emergencia de formas novedosas de organización social que quiebran los esquemas establecidos. Es la era de la Modernidad reflexiva, la segunda Modernidad (Beck, 1997; Beck, 2001) o la Modernidad líquida (Bauman, 2002), que se caracteriza por la aceleración de las coordenadas espaciotemporales, el impacto de las nuevas tecnologías, el pluralismo social y político, la inmigración, el renacimiento o la aparición de nuevas identidades, la crisis de la razón totalizadora y la quiebra de modelos sociales y políticos característicos de la primera Modernidad.

Todos estos cambios sociales apuntan hacia un cambio de paradigma cultural, cuya irreversibilidad sería consecuencia de la constante mutación de la organización social, a partir de la 
irrupción de las nuevas tecnologías. Entre los rasgos fundamentales de esa situación de crisis, Faria advierte los siguientes:

a) el surgimiento de nuevas fuentes de producción jurídica que apunta a la multiplicación de actores jurídicos en el escenario supra e infraestatal;

b) el policentrismo decisorio que contrarresta la concentración de poder en los Estados y debilita crecientemente su poder y capacidad;

c) la tendencia a la desregulación, a la deslegalización y a la contractualización de fenómenos sociales, que se traduce en una retirada de la normatividad jurídica y en una mutación profunda de su funciones y alcance, y

d) la aparición de una nueva estructura de la normatividad jurídica de carácter eminentemente reticular, con un retroceso significativo de los principios de unidad, racionalidad y estatalidad, lo cual suscita la necesidad de pensar el Derecho desde nuevos paradigmas ajenos al formalismo de épocas pretéritas (Faria, 2008: 31 ss.).

En ese contexto, se producen significativas transformaciones en el ordenamiento jurídico, en la estructura de la producción normativa, en el sistema de los derechos fundamentales y en el armazón conceptual que lo sostiene y le da soporte, propiciando un giro desde la unidad al pluralismo, desde la plenitud a la apertura jurisdiccional y desde la coherencia a la argumentación, que conducen a una concepción policéntrica del ordenamiento y hace sucumbir definitivamente el horizonte explicativo del positivismo jurídico ${ }^{1}$.

En definitiva, la globalización se cifra en la apertura de una nueva era de desarrollo del sistema capitalista, un nuevo ciclo de expansión del capitalismo como modo de producción $\mathrm{y}$ proceso civilizatorio de alcance mundial (Ianni, 1999: 11); en ese nuevo escenario, las fuerzas libres de la economía ganan preponderancia y capacidad directiva sobre los diferentes órdenes de la vida social, empujadas por la integración de los mercados de forma avasalladora y por la intensificación de la circulación de bienes, servicios, tecnologías, capitales e informaciones a nivel planetario.

De este modo, la globalización aparece concebida como la "integración sistémica de la economía a nivel supranacional, deflagrada por la creciente diferenciación estructural y funcional de los sistemas productivos y por la subsiguiente ampliación de las redes empresariales, comerciales y financieras a escala mundial, actuando de modo cada vez más independiente de

\footnotetext{
1 Como consecuencia de ello, se produce una crisis de la morfología piramidal y jerarquizada del ordenamiento jurídico que es suplantada por una estructura de bóveda, como consecuencia de la confluencia e interacción entre diferentes normatividades. En ese horizonte, la totalidad del sistema se obtiene por la superposición de estructuras normativas de procedencia heterogénea. Pérez Luño se distancia, de este modo, de las tesis recientes que tienden a explicar la estructura actual del ordenamiento jurídico en clave reticular (Pérez Luño, 2016: 3436).
} 
los controles políticos y jurídicos a nivel nacional" (Faria, 2000: 52).

Es lo que Wallerstein ha denominado economíamundo: un nuevo marco económico mundial regido por el sistema capitalista cuya dinámica expansiva alcanza así su culminación. De un extremo a otro del planeta, el capitalismo se extiende y se ramifica en múltiples derivaciones locales, un único sistema cuyos desdoblamientos crean una imagen de particularidad. La economíamundo aparece, entonces, como un marco de referencia regido por tres elementos básicos:

a) el principio de maximización de los beneficios; b) la existencia de estructuras estatales que intervienen en los procesos económicos, en aras de la máxima productividad de determinados grupos; $\mathrm{y}$

c) la estratificación del espacio internacional, en virtud de las condiciones de explotación que imperan en las relaciones entre Estados, como consecuencia de un orden económico internacional inicuo (Wallerstein, 1979 y 1991).

Estas alteraciones de la economía provocan un conjunto concatenado de reacciones que van desde la disminución de la capacidad de reglamentación de los gobiernos a la aparición de nuevas configuraciones geopolíticas con poder para controlar los flujos productivos, mercantiles, monetarios y migratorios (Faria, 2000: 7-8).
La globalización genera una multiplicidad de conexiones y relaciones entre Estados y sociedades, multiplicidad que trastoca y que quiebra los esquemas de un orden socio-político basado en la diferenciación a través de las estructuras propias de los mercados nacionales. La globalización es algo más que un proceso de superación de las economías parciales de los Estados y su suplantación acelerada por un único espacio de intercambio de carácter global.

Implica, fundamentalmente, un salto cualitativo en la expansión del capitalismo, un capitalismo que, al desvincularse del modelo económico estatal, se convierte en apátrida, un capitalismo sin raíces y $\sin$ territorio, en un escenario de expansión del derecho contractual, de minimización del ius cogens, de auge de las normatividades difusas y del soft law y de desregulación y deconstitucionalización, que alcanza al reconocimiento, garantía y efectividad de los derechos humanos ${ }^{2}$.

La interconexión, propiciada por las comunicaciones y por las nuevas tecnologías, ha provocado la reducción espacial del mundo, cuyos confines resultan ahora fácilmente abarcables $^{3}$. No hay camino inexplorado ni tierra

\footnotetext{
${ }^{2}$ El impacto de la globalización sobre los derechos humanos en el ámbito de las relaciones iusprivatísticas a partir de la responsabilidad social corporativa ha sido recientemente estudiado en un interesante trabajo por Belloso (2013).

3 Con indiscutible fuerza expresiva, Bauman ha reflejado esta situación en los siguientes términos: "...el capital se ha hecho
} 
ignota: lo desconocido ya no existe. Evocando la tesis de Fukuyama sobre el fin de la historia, Richard O'Brien ha proclamado el fin de la geografía: las distancias ya no importan y la idea de frontera geográfica es cada vez más insostenible en el mundo real. En efecto, la distancia no es un dato objetivo, sino que es, ante todo, un producto social, una magnitud relativa asociada a la capacidad humana para salvarla (Bauman, 1999: 19 ss.). En nuestro tiempo no hay nada demasiado lejano e inaccesible ${ }^{4}$.

En este sentido, nuestra era viene marcada por dos fenómenos fundamentales: a) la reducción del espacio geográfico y b) la creación del espacio cibernético. Una red de comunicaciones abraza el planeta de un extremo a otro: carreteras, rutas marítimas y aéreas, satélites, fibra óptica, ondas electromagnéticas... Un manto tupido y enmarañado de comunicaciones que elimina los obstáculos y diluye las fronteras (Shawcross, 1993). Los límites se difuminan y desaparecen, las puertas se abren, las dificultades se allanan.

extraterritorial, ligero, sin estorbos y desincrustado hasta un extremo sin precedentes, y el nivel de movilidad espacial que ya ha alcanzado es suficiente para chantajear a los organismos políticos vinculados con el territorio para que se sometan a sus exigencias. (...) Habiendo soltado el lastre de la maquinaria voluminosa y las enormes dotaciones de las fábricas, el capital viaja ligero, sólo con equipaje de mano: una cartera, un ordenador portátil y un teléfono celular" (Bauman, 2001: 36-37).

${ }^{4}$ Bauman cita a Paul Virilio (1997: 17). Matiza, sin embargo, que el origen de la tesis del fin de la geografía debe localizarse en Richard O'Brien (1992).
Los vínculos se multiplican, las fronteras se diluyen, se estrechan los lazos y se difuminan las relaciones jerárquicas. La sociedad interconectada o global se nos prefigura ya como un fenómeno irreversible. Entre las causas que auspician esta conclusión deben considerarse:

a) la red de telecomunicaciones a nivel global;

b) la creación de un mercado global de bienes y servicios;

c) los flujos migratorios y su impacto en la economía, la demografía y el medio ambiente;

d) la expansión de la democracia y de los valores que la sustentan;

e) la progresiva creación de una sociedad civil global (Held, 2012: 145).

Frente a la morfología piramidal de los sistemas sociales, nuestra era emerge como la sociedad red: una sociedad construida por la revolución de las tecnologías de la información y la reorganización del capitalismo. La sociedad red representa un nuevo modelo de organización socioeconómica, mediante la globalización de las actividades económicas y el desarrollo de un sistema de medios de comunicación omnipresentes, interconectados y diversificados.

La acción combinada de estos elementos ha provocado una "transformación de los cimientos materiales de la vida, el espacio y el tiempo, 
mediante la constitución de un espacio de flujos y del tiempo atemporal" (Castells, 1998: 23).

El capitalismo se expande a ritmo de vértigo, los intercambios se multiplican, y el dinero se mueve por los circuitos virtuales de la telemática: nuevos flujos financieros que escapan a todo control. En este escenario, los Estados-nación pierden de manera alarmante su propia capacidad de dirección, de regulación y de control sobre los procesos socio-económicos.

Estamos, en suma, ante una "crisis generalizada del estado-nación" (Ianni, 1999b: 17). Y es que esos nuevos fenómenos históricos sintetizados en el término globalización, "desgarran el tejido conceptual de la "teoría política" moderna" (Capella, 2000: 104).

La teoría política tradicional ha perdido capacidad explicativa ante el empuje de este vasto conjunto de fenómenos que limita fácticamente el propio ámbito de actuación del Estado como actor principal del orden jurídico-político, de modo que la mundialización subvierte el mercado nacional para hacerlo global y, consecuentemente, ajeno a las estructuras territoriales del Estado-nación (Capella, 2000: 106; Ferrajoli, 2005: 397 ss.).
2. La gestión del riesgo en la era de la globalización

Vivimos, por tanto, un periodo complejo, de cuestionamiento profundo de formas civilizatorias $\mathrm{y}$ culturales en un escenario de cambios vertiginosos y de acoso a los pilares del proyecto ilustrado. Esta situación se agudiza ante la evidencia de que las transformaciones culturales que se están operando en nuestro mundo nos conducen hacia una realidad desconocida que precisa, también, nuevos paradigmas.

En esas coordenadas, justamente, han irrumpido con fuerza en las últimas décadas, las tesis postmodernas y las nuevas versiones del relativismo, auspiciadas por determinadas variantes del multiculturalismo y del pluralismo jurídico ${ }^{5}$ que, a pesar de sus diferentes fuentes teóricas y sus matices diferenciales, confluyen en la crítica acerba a las grandes metanarraciones de la Modernidad, asociadas al discurso universalista sobre los derechos humanos.

Veamos, a continuación, en qué medida el cuestionamiento general de la razón ilustrada, asociado a los cambios tecnológicos que están

\footnotetext{
${ }^{5}$ Una estimulante variante del pluralismo jurídico, en el contexto latinoamericano, nace en el seno del pensamiento crítico de aquel continente, asociado a lecturas emancipatorias, anticolonialistas y contrahegemónicas, y encuentra una vigorosa expresión en la obra de A.C. Wolkmer en Brasil y O.Correas y J. A. de la Torre Rangel en México y D. Sánchez Rubio en España (Para una perspectiva general de esta amplia y rica corriente teórica, cfr. Wolkmer et al., 2010).
} 
alterando drásticamente las relaciones del hombre con la naturaleza y transmutando, de manera decisiva, nuestra imagen del mundo, alcanzan a nuestra comprensión del Derecho moderno.

Nos interesaremos, particularmente, en la incidencia de ese cuestionamiento en relación con el paradigma de los derechos humanos y la protección del medio ambiente. Nuestro objetivo último es responder a la cuestión sobre si, en las coordenadas de la sociedad del riesgo global acogiéndonos a la terminología con la que Ulrich Beck ha caracterizado la era presente- ese paradigma debe ser redefinido y en qué sentido.

La actual reacción contramoderna ataca desde sus cimientos a la razón, como posibilidad teórica de abstraer y universalizar, estableciendo, en el ámbito jurídico-político, principios generales de convivencia y organización. Aquí podríamos invocar a Erhard Denninger, quien no duda en aseverar que esta reacción contra el proyecto de la Modernidad puede caracterizarse como una “crisis generalizada de la razón”, incluso podría hablarse sencillamente del "final de la razón en general'”.

Éste es el elemento principal en base al cual se puede justificar la separación entre el Derecho de la época de las luces y la Revolución Francesa y el actual Derecho postmoderno. Lo que caracteriza, pues, a este nuevo Derecho es, más que la desaparición de la razón teórica, el declive de la razón práctica como elemento constitutivo del saber y del hacer humanos que posibilita alcanzar compromisos universales. La pérdida de esta orientación capital de la Modernidad tiene su causa en el crecimiento de los niveles de inseguridad en las sociedades contemporáneas, que afecta al desarrollo del saber científico, provocado fundamentalmente por tres circunstancias:

a) La primera de ellas es el creciente nivel de riesgo en el manejo de los medios técnicos que los avances científicos han proporcionado; nivel de riesgo que provoca inseguridad.

No se conocen bien las consecuencias de nuestros propios actos en el manejo de las tecnologías y existe una sensación general de desprotección ante eventuales catástrofes tecnológicas. Hemos creado una tecnología altamente sofisticada, que a veces no somos capaces de dominar, lo cual genera inseguridad.

Esto nos conduce, necesariamente, a lo que Beck ha denominado sociedad del riesgo, que supone la obsolescencia de la sociedad industrial. Se trata de una nueva fase de desarrollo de la sociedad moderna en la que los riesgos sociales, económicos, políticos e individuales escapan de forma creciente al control de las instituciones y de las estructuras. Paulatinamente, los peligros de la sociedad comienzan a dominar los debates y conflictos públicos y privados. Como 
consecuencia de ello, son las instituciones las que sufren una crisis profunda de legitimación, al convertirse en productoras de amenazas que no pueden controlar.

La modernización genera así una tendencia incontrolable que conduce a una nueva situación: la de la obsolescencia de la sociedad industrial para controlar y someter las tendencias que ella misma ha creado. De este modo, el concepto de sociedad del riesgo plantea una transformación en tres áreas:

1. la relación de nuestra sociedad con los recursos de la naturaleza y de la cultura, que están siendo dilapidados bajo el torbellino de la razón instrumental;

2. los paradigmas sociales de seguridad, que están siendo desbordados por la dinámica de un riesgo que no puede ser neutralizado;

3. el agotamiento de los referentes significativos de los grupos sociales que han estructurado nuestra sociedad (p.e., conciencia de clase, fe en el progreso, etc...), cuyo derrumbamiento genera indefinición y anomia (Beck, 1997: 18-20; Climent, 2006; Serrano, 2010).

b) La segunda circunstancia está constituida por lo que Denninger llama "explosión de ignorancia", que constituye una de las características constitutivas del saber posmoderno, y cuyas consecuencias afectan a la estructura del Estado de Derecho y a la función del "Derecho regulador".

La ampliación de los horizontes de conocimiento en el campo del saber científico implica, paralelamente, la ampliación del horizonte de desconocimiento, en la medida en que, cuanto más se sabe, más consciente se es de lo mucho que resta aún por saber.

Las incertidumbres amenazan, incluso, la estabilidad del conocimiento pretendidamente seguro; y esta paradoja afecta no sólo a zonas marginales de la ciencia, sino que repercute sobre ámbitos de relevancia técnica inmediata (por ejemplo: ¿cuáles serán las consecuencias a medio plazo de los cambios climáticos o del agujero de la capa de ozono?; ¿volverá a repetirse en algún otro rincón del planeta catástrofes como las de Chernobyl o, más recientemente, Fukushima?; ¿qué riesgos implican para el futuro de la humanidad los nuevos avances en genética?).

Para ilustrar algunos de los anteriores interrogantes, Denninger cita una sentencia del Tribunal de lo Contencioso-Administrativo de Kassel en la que, al considerarse la necesidad de obtener licencia para unas instalaciones experimentales de manipulación genética, el Tribunal decide dejar a un lado los mecanismos tradicionales de argumentación propios del Estado de Derecho. En la citada sentencia, el tribunal no fundamenta su resolución ni en la 
teoría de la norma general excluyente -en virtud de la cual, al no estar expresamente prohibida, dicha actividad debe entenderse permitida-, ni en la interpretación más amplia posible -favor libertatis- de ciertas libertades constitucionales (como las de ejercer oficio y actividad económica).

Por el contrario, el tribunal se transforma en legislador, estableciendo un "programa de seguridad preventivo" $y$, en virtud de ello, prohíbe la actividad, invirtiendo la relación prohibido-permitido, de la siguiente forma: "Puesto que la puesta en práctica de este tipo de actividades no está expresamente permitida, sino condicionada a severos controles, debe estar en principio prohibida en función de sus imprevisibles riesgos". Y al hacer ésto, crea un amplio margen de inseguridad, ya que el ciudadano se vería abocado a la incertidumbre a la hora de someter a la consideración de los tribunales la evaluación de cualquier actividad de tipo técnico (Denninger, 1996: 64-65; Warat, 1996: 157$)^{6}$.

Las consecuencias de este fenómeno se miden en términos de "crisis del Estado de Derecho", en la

\footnotetext{
${ }^{6}$ La situación a la que alude Denninger es planteada también por Luis Alberto Warat al referirse a la inflación informativa de nuestro tiempo, que provoca que los grandes principios pierdan consistencia y valor: "El Derecho parece estar también afectado por la metástasis informativa de la transmodernidad. Temas que hacen a la solidaridad, a la democracia, a los Derechos Humanos, la ciudadanía, la censura, o al ejercicio de los Derechos, son alterados por una sobredosis de información que les hacen perder consistencia, casi como si no existieran" (Warat, 1996: 157).
}

medida en que los medios tradicionales de aplicación e interpretación del Derecho se revelan inútiles. Si no puede determinarse con exactitud el causante de un daño, si tampoco puede delimitarse el hecho jurídico como consecuencia del cual nace la responsabilidad, ¿de qué sirve entonces el "Derecho regulador"?

Se desdibujan, entonces, los límites aparentemente claros entre lo prohibido y lo permitido. Al difuminarse el límite entre seguridad y previsibilidad del Derecho y, con él, la libertad y responsabilidad del ciudadano, cambiaría igualmente la seguridad precaria, preventiva, manipulable y contextual en relación a determinados bienes jurídicos. Y con ello, "la relación entre la generalidad de la Ley, entre el sujeto responsable de sus actos... y la superación técnico-racional del mundo, dicha relación todavía brillaría un último segundo con todo su esplendor, justo en el momento de su desaparición" (Denninger, 1996: 65).

c) la última circunstancia afecta a la relación saber-poder, que se ha visto considerablemente redimensionada por la creciente influencia de los avances científico-técnicos en la concreción de estructuras de poder en la sociedad.

En consecuencia, se puede detectar una creciente implicación de las estructuras de poder y del desarrollo científico, lo cual tiene una dimensión cotidiana: la desintegración de los modelos 
tradicionales de identidades colectivas como el Estado nacional, la clase social, la creencia religiosa o el partido político. Como consecuencia de esta redefinición de la relación saber-poder, hay categorías básicas del pensamiento jurídicopolítico que precisan ser repensadas (Denninger, 1996: 61-66).

No podemos seguir ignorando que tenemos una mutación importante ante nosotros, una mutación que exige un cambio de perspectivas y de instrumentos para pensar el modelo de sociedad y de Derecho que queremos para el futuro. Y realmente esta mutación afecta al saber de nuestro tiempo.

Ya no nos sirven muchas de las categorías tradicionales que conforman el Estado de Derecho y el sistema jurídico que dio a luz la Modernidad. En algún sentido, sus conceptos precisan ser reformulados. La imaginación del jurista y del teórico del Derecho tiene que realizar esfuerzos creativos, si no queremos quedarnos anclados en un saber que está comenzando a dejar de ser útil para explicar y resolver los grandes problemas a los que nos enfrentamos; problemas a escala planetaria cuya dimensión temporal rebasa los confines del presente.

Esa transformación implica, desde el punto de vista ecológico, un nuevo marco conceptual que Crutzen ha denominado antropoceno, como expresión de una nueva fase en el desarrollo geológico del planeta, que tiene, en la acción humana, el factor más decisivo de las transformaciones que se están operando en las últimas centurias, sobre el espacio biofísico. La acción transformadora del ser humano incide sobre el desarrollo medioambiental generando mutaciones que amenazan la preservación del planeta (Crutzen, 2002).

La creciente conciencia de esa realidad y los desequilibrios y catástrofes que genera, requieren, en consecuencia, respuestas jurídicas adecuadas para hacer frente al desafío de la preservación ambiental en un contexto de creciente deterioro ambiental que afecta a la especie humana en su conjunto.

Los nuevos problemas que el Derecho ha de afrontar hablan de espacios sin fronteras, casi podríamos decir sin horizontes, y de tiempos que están por venir. Ya no son problemas de nuestra sociedad, de nuestro país o de nuestra generación. Las más acuciantes demandas a las que el Derecho habrá de ir dando respuesta tienen, con frecuencia, un alcance geográfico mundial y afectan no sólo a nuestra generación, sino a las generaciones venideras.

Si el Derecho de la Modernidad incorporó la dimensión del progreso en la contemplación del presente, desde una perspectiva de optimismo antropológico; nosotros, si queremos preservar ese optimismo, deberemos incorporar la 
dimensión global de los problemas en la contemplación del futuro.

\section{La protección de los derechos en la sociedad}

\section{del riesgo}

En este contexto se hace cada vez más patente que la globalización entraña desafíos de singular relevancia en el proceso de desenvolvimiento histórico de los derechos humanos, que atraviesan, en este periodo de redefinición de las ciencias sociales en general, un momento particularmente crítico.

La intensificación de los intercambios económicos a través de las nuevas tecnologías, la expansión frenética del capitalismo y la creación de macropoderes económicos transnacionales, inaccesibles al control democrático de la ciudadanía, ponen de manifiesto una nueva fase de desarrollo del capitalismo que plantea retos también nuevos para la teoría de los derechos humanos ${ }^{7}$.

\footnotetext{
${ }^{7}$ Evidentemente, ello conecta con: a) los planteamientos sobre la justicia distributiva global y la extensión de los derechos más allá del marco estatal, cuestiones que, a su vez, remiten al debate actual sobre la viabilidad de un constitucionalismo cosmopolita (Turégano, 2010). En una línea complementaria, Barranco Avilés se introduce en la fundamentación de una teoría de la justicia basada en la igual dignidad de los seres humanos en el marco del constitucionalismo contemporáneo (Barranco, 2012); b) la concepción cooperativa de los derechos como razones para la acción internacional, que sitúa a los individuos como miembros de la comunidad internacional y que recaba una gobernanza cooperativa entre instituciones a nivel local, regional y mundial (Iglesias, 2016).
}

La eclosión del nuevo orden económico global hace cada vez más evidente la crisis de todo un modelo de comprensión de los derechos humanos como categorías vinculadas espaciotemporalmente, cuya satisfacción excluyente queda restringida al limitado espacio estatal y a la dimensión temporal del presente.

Puede decirse que la globalización inaugura una nueva fase en el decurso histórico de los derechos humanos; una fase marcada por la demanda de una comprensión cabal y completa de los derechos como categorías insertas de lleno en la realidad histórica en la que se explicitan.

Si hasta ahora los derechos humanos han sido concebidos de forma fragmentaria y parcial, asociados al anclaje territorial del Estado y vinculados a la causación de un daño real en el tiempo presente, el horizonte de la globalización exige superar esta suerte de planteamientos estancos e incompletos que son la causa de muchos dislates en el desarrollo de los derechos humanos.

Asistimos, por tanto, a una crisis del paradigma espacio-temporal de los derechos humanos, cuya insuficiencia se hace cada vez más patente, al constatarse que la universalización de los derechos humanos resulta incompatible con ese paradigma. ¿Cuáles son los elementos de éste, cuya vigencia constituye hoy un importante 
obstáculo teórico a la realización universal de los derechos humanos?

En mi obra En las Encrucijadas de la Modernidad, sostuve, a propósito de la crisis del paradigma jurídico de la Ilustración, la necesidad de una reformulación del paradigma jurídico que reconciliara la racionalidad de los fines con la racionalidad instrumental, y que allanase el camino a una concepción de la justicia que superase el reducido marco de las fronteras estatales. Al hilo de ello, argumenté que el Derecho moderno debía liberarse de algunos lastres que impedían soltar amarras en esa nueva travesía que había que iniciar.

Parece conveniente, ahora, volver sobre lo que expuse entonces para retomar dos aspectos principales que cobran inusitada importancia en este momento y que, aplicados a la teoría de los derechos humanos, constituyen los ejes de ese paradigma espacio-temporal que entra en irremediable crisis en este tiempo de riesgos impredecibles y de magnitudes insospechadas. Efectivamente, esa nueva dimensión del riesgo en un mundo tecnológicamente hiperdesarrollado, fuerza una nueva concepción del Derecho y de los derechos y nos coloca, en mi opinión, ante dos grandes evidencias:

a) En primer lugar, es necesario superar el reducido espacio de las fronteras estatales. En los tiempos de la globalización, el marco político estatal se revela cada vez más insuficiente, ante la constatación de riesgos de alcance global y de amenazas fatales e irreversibles para el género humano. Ha adquirido notoriedad el aserto en virtud del cual, en la era contemporánea, el Estado resulta demasiado grande para las cosas pequeñas y demasiado pequeño para las cosas grandes (Bell, 2006).

Refiriéndose a esta cuestión, Ulrich Beck ha afirmado que asistimos al ocaso de una premisa esencial de la primera Modernidad, aquella que vinculaba la acción a espacios delimitados geográficamente en los contornos del Estadonación. La globalización entraña la disolución de las acotaciones territoriales, el fin de las fronteras y de las separaciones artificiales.

Todo aparece ya interconectado: la economía, la información, la ecología, la técnica, los conflictos transculturales y la sociedad civil: "Así entendida, la globalización significa la muerte del apartamiento, el vernos inmersos en formas de vida transnacionales a menudo no queridas $e$ incomprendidas" (Beck, 1998: 42-43).

En este contexto, se hace necesario implementar estructuras institucionales de ámbito supranacional que permitan dar respuesta a problemas que van más allá de las reducidas fronteras del Estado-nación. La paradoja de nuestro tiempo se cifra, precisamente, en la alarmante sensación de que nos enfrentamos a 
gigantes con tirachinas, que los problemas exceden de las capacidades reales de la estructura político-institucional de la que nos hemos dotado y que ésta se ve desbordada por la dinámica de los acontecimientos sociales, en un escenario que es ya irreversiblemente transnacional (Held, 2012: 209).

En otro lugar, he subrayado la necesidad de superar la dispersión de los múltiples centros jurídicos estatales, respondiendo a las pulsiones globales con un esfuerzo universalizador, que permitiera contrarrestar las tendencias negativas que el proceso de globalización comporta (De Julios-Campuzano, 2000: 299; Bolzán, 2011), desde una óptica de reconocimiento de las aportaciones de la Modernidad jurídica, cuyos elementos determinantes representan, al decir de Streck, "marcos civilizatorios insuperables" (Streck, 2016: 50).

En lo que concierne a la teoría de los derechos humanos, el horizonte espacial de la Modernidad ha generado una concepción de éstos estrictamente vinculada al Estado-nación que, al apostar por la realización de los derechos humanos como derechos ciudadanos, sacrifica su propia matriz ilustrada de cuño universalista, asociando $\mathrm{su}$ reconocimiento universal a su concreta adscripción e implementación en el marco del ordenamiento jurídico estatal. Los derechos humanos quedan, en consecuencia, indisociablemente unidos al ámbito geográfico circunscrito por el principio de soberanía nacional, tanto al nivel interno de cada Estado como en el escenario inter-nacional, en el que el Estado sigue apareciendo como el principal actor del orden jurídico-político. De este modo, la realización de los derechos humanos es contemplada como una tarea fragmentaria $y$ excluyente que descansa sobre la afirmación dogmática de la soberanía nacional como límite en la realización de los derechos (Ferrajoli, 2011a; Bolzán, 2011).

Por otra parte, la emancipación del sistema económico convierte a los Estados en instrumentos serviles del capitalismo transnacional. El contexto internacional se puebla, así, de un conjunto de Estados, cada uno de los cuales pugna por cumplir las demandas y expectativas de sus nacionales con respecto a la realización de los derechos fundamentales.

El escenario internacional se convierte, así, en un campo de batalla en el que los Estados tratan de satisfacer, a toda costa, las expectativas de bienestar y desarrollo de sus ciudadanos, en detrimento, si necesario fuere, de los derechos de otros nacionales.

La lógica de la racionalidad económica se convierte, entonces, en la pauta que los Estados adoptan para la realización de los derechos. Y así, los países ricos logran altos niveles de bienestar al 
precio de la privación y la miseria de los países más pobres. De esta suerte, la satisfacción de los derechos entra en una dinámica excluyente que se agudiza cuando se contempla la existencia de derechos insostenibles, por cuanto que propician actitudes y comportamientos lesivos para la preservación del medio ambiente.

El deterioro del medio ambiente, la contaminación y la disposición de los recursos no renovables no pueden encontrar justificación en interpretaciones atomistas de determinados derechos como la propiedad, la libre circulación de mercancías o la libertad de empresa (Mercado, 2012a; Mercado 2012b). Frente a ello, precisamos reaccionar articulando soluciones para implementar la gobernanza de los riesgos globales en el ámbito supranacional, singularmente, los riesgos financieros, de seguridad y medio ambientales (Held, 2012: 177 ss).

b) En segundo lugar, la dimensión temporal de los problemas, propia del Derecho moderno, supeditaba la constatación del conflicto a su concreta configuración en el presente, de modo que un bien jurídico sólo se consideraba lesionado ante un daño real y efectivo. Las circunstancias de la innovación tecnológica en nuestra era convierte en tema de indudable actualidad el nivel de riesgo en el manejo de los avances tecnológicos.

Nuestras sociedades comienzan a ser conscientes de los riesgos imprevisibles que se pueden derivar del uso de las nuevas tecnologías, que pueden poner en peligro la propia continuidad de la especie y la preservación del planeta. Surge, entonces, la necesidad de incorporar una mirada ecológica hacia nuestro entorno, que haga posible la reconciliación del hombre con su hábitat natural: nuestros problemas no se miden ya en términos de lesiones actuales y efectivas a los bienes jurídicos, sino que exigen la incorporación de una dimensión futura ${ }^{8}$.

Urge, pues, implementar la dimensión del futuro en la catalogación de los conflictos jurídicos, si queremos resolver algunas de las grandes interrogantes que afectan al género humano.

Frente a la causación del daño y a su eventual reparación, hemos de oponer -singularmente en el ámbito medio ambiental, de la distribución de los recursos y de las condiciones de vida sobre el planeta-, un derecho de prevención de riesgos que, anticipando la dimensión temporal del futuro, salvaguarde el interés, no por difuso menos digno de protección, de las generaciones futuras a una vida digna (De Julios-Campuzano, 2000: 300).

\footnotetext{
${ }^{8}$ En esa línea, M. Ruiz propugna los contornos de un paradigma jurídico ambiental al que atribuye, significativamente, entre otros rasgos: un sentido espacial singular, puesto que abarca cuestiones que tienen alcance global, la primacía de los intereses colectivos, y una vocación redistributiva pues responde a una aspiración internacionalizadora y, en algun sentido, solidaria. Ese paradigma jurídico responde además a una orientación preventiva, tendente a evitar la producción de daños ambientales irreparables o imprevisibles (Ruiz, 2012: 129-132).
} 
Se trata así de responder a la espiral de riesgo creciente en el que nuestras sociedades se han instalado, complementando la dimensión reparadora de la normatividad jurídica, con normas de carácter preventivo, orientadas a minimizar la potencialidad destructiva de las amenazas que se ciernen sobre la humanidad toda.

Las secuelas del desarrollo científico-tecnológico repercuten en el sistema jurídico, que se ve abocado a articular respuestas de carácter preventivo que eviten la causación del daño. En términos de Derecho ambiental ya no es suficiente el principio en virtud del cual "quien contamina paga".

No se trata de reparar el daño, porque en muchos casos puede resultar irreparable: la pérdida de la diversidad biológica, la contaminación de los ríos, el calentamiento global del planeta, el agujero de la capa de ozono o la contaminación de los acuíferos subterráneos, son sólo algunos ejemplos de las amenazas reales que se derivan de este uso incontrolado de los avances científicotecnológicos (Denninger, 1996: 53-70).

Ante ello, a partir de la década de los 90 del pasado siglo, se ha afirmado, primero, $y$ afianzado, después, en el Derecho contemporáneo, el principio de precaución (vorsorgeprinzip) que demanda una actuación efectiva en orden a evitar situaciones de riesgo grave e inminente en el ámbito de la salud o del medio ambiente y que contribuye a diseñar un nuevo paradigma del Derecho y de las políticas públicas en esta era en la que las amenazas imprimen un nuevo sesgo hasta ahora desconocido a la organización política y jurídica, desafiando la arquitectura jurídica de la Modernidad vertebrada en torno al imperio de la ley (De Cózar, 2005: 133; Hanschel, 2006: 179184).

Este tiempo convulso de la globalización inaugura una era trepidante en la que los acontecimientos se suceden a velocidad de vértigo y el marco temporal de la primera Modernidad queda definitivamente sobrepasado. Asistimos a la quiebra del paradigma temporal de la Modernidad vinculado al presente: un proceso de “desreferencialización" temporal que nos hace sensibles a incertidumbres inquietantes, que nos deja inermes ante amenazas y riesgos nunca antes conocidos.

Las innovaciones científico-tecnológicas incrementan la sensación de desasosiego y de zozobra. Es la "sociedad del riesgo mundial" acuñada por Beck: una sociedad que se sabe vulnerable, en la que las amenazas se prolongan temporalmente hacia el futuro (Beck, 2008; Beck, 1998; Beck, 1997: 65-71; Giddens, 2000: 33-48).

Somos conscientes de que las tecnologías son portadoras de riesgos imponderables e imprevisibles y nos sentimos inseguros. Una 
sensación global de precariedad ante estas amenazas más que potenciales nos une a nuestros congéneres en una reacción solidaria de cuño cosmopolita. La demanda creciente de seguridad nos proyecta hacia el futuro, en un afán por perpetuar la vida y por preservar el planeta, y surgen, entonces, “intereses difusos" que reclaman protección.

En la sociedad del riesgo todo aparece difuminado: "los denominados peligros globales hacen que se resquebrajen los pilares del tradicional sistema de seguridad. Los daños pierden su delimitación espacio-temporal para convertirse en globales y permanentes. Los daños apenas si se pueden seguir atribuyendo a unos responsables determinados; el principio de causalidad pierde capacidad segregadora" (Beck, 1998: 70).

\section{La universalización de los derechos humanos y la justicia intergeneracional}

Sensible a esta demanda de seguridad y a la preocupación creciente por la preservación del medio natural y de las condiciones que permitan la continuidad de la especie, la Corte Internacional de Justicia ha venido elaborando una concepción de equidad intergeneracional basada en los derechos equitativos de las generaciones futuras a un medio ambiente sano y equilibrado, cuya preservación sea compatible con el desarrollo tecnológico.

Ha comenzado a abrirse paso, así, a nivel internacional, una nueva concepción de los derechos de carácter vertical, que se proyecta en el futuro para contemplar la equidad intergeneracional y el derecho de las generaciones futuras a una vida digna.

Esa dimensión vertical de la justicia conecta con el concepto de justicia ambiental que incide sobre la dimensión horizontal y sincrónica, y recaba actuaciones y medidas concretas en orden a la reconciliación del hombre con el medio ambiente en evitación de la esquilmación de los recursos naturales, la devastación del planeta y la evitación de catástrofes ambientales que comprometen severamente la coexistencia.

De ahí deben desprenderse, consecuentemente, obligaciones del hombre para con sus congéneres, para cuantos conviven en el planeta que, en cuanto casa común debe ser cuidada en aras de la calidad de vida y del bienestar que demandan de nosotros actuaciones responsables que no comprometan la preservación del medio ambiente.

El derecho internacional debe articular, por tanto, las obligaciones recíprocas de los estados en la consecución de esta prioridad de nuestro tiempo, insertando esta exigencia en el contexto de las 
relaciones complejas entre el norte y el sur, entre los países desarrollados y los países en vías de desarrollo (Anand, 2016: 3 ss.).

Pero esa dimensión horizontal precisa ser completada con una dimensión vertical, que concierne al futuro $\mathrm{y}$, por ende, al valor proyectivo de los derechos. El planeta no puede ser esquilmado, y las generaciones presentes tienen que "administrar" el legado recibido para evitar daños ecológicos y ambientales irreparables que puedan comprometer los intereses difusos de las generaciones venideras.

De este modo, el impacto de las nuevas tecnologías, en una época de riesgos crecientes cuyas consecuencias pueden resultar imprevisibles, contribuye a redefinir el horizonte de los derechos humanos y nos permite atisbar una dimensión proyectiva de los bienes jurídicos que han de ser protegidos y preservados en una doble dimensión:

a) en sentido horizontal, apostando por una distribución equitativa de los bienes a nivel global y salvando la quiebra en la distribución de la riqueza entre las generaciones actuales;

b) en sentido vertical, incorporando una concepción de la justicia que contempla, también, los intereses de las generaciones futuras y la existencia de deberes por parte de las generaciones actuales en relación con la conservación de los recursos naturales y la preservación medioambiental.

Precisamos, por ende, incorporar una concepción intergeneracional de la justicia a nuestra forma de pensar el desarrollo, la competitividad y la productividad. De lo contrario, el daño ambiental puede tener consecuencias irreparables para el desarrollo de las condiciones que permitan una existencia digna. Afrontar el reto de construir un modelo de competitividad sostenible es una necesidad inaplazable.

La idea de justicia intergeneracional parte del reconocimiento de que cada generación es depositaria de un legado natural y cultural que ha recibido de las generaciones precedentes y que ha de transmitir a las generaciones futuras. Esta relación impone ciertas obligaciones planetarias, al tiempo que brinda a cada generación ciertos derechos planetarios, en tanto que beneficiarios del fideicomiso recibido de sus antepasados. En este sentido, Edith Brown propone tres principios básicos de la equidad intergeneracional, a saber:

a) cada generación debe ser compelida a conservar la diversidad de recursos naturales $y$ culturales y tiene, derecho, además, a una diversidad comparable a la de las generaciones precedentes. Una restricción en este sentido afectaría a las opciones disponibles a las futuras generaciones (principio de conservación de opciones); 
b) cada generación está obligada a preservar la calidad del planeta tal como lo ha recibido de las generaciones precedentes (principio de conservación de la calidad);

c) cada generación debe proporcionar a sus miembros derechos equitativos de acceso al legado de generaciones pasadas, preservando este derecho para generaciones futuras (principio de conservación de acceso) (Brown, 1999: 36-41 у 69).

De este modo, el concepto de justicia intergeneracional comporta un compromiso con la especie y una reconciliación del hombre con su hábitat natural (Jonas, 1995; Arribas, 2009, Grosseries, 2015; Lema, 2015). A través de diversos pronunciamientos jurisprudenciales va adquiriendo carta de naturaleza una concepción vertical de la justicia que vincula a las generaciones presentes con las generaciones futuras y de la cual surgen obligaciones, reglas y actitudes "basadas en un concepto de distribución equitativa que era a la vez horizontal en relación con la generación actual y vertical en cuanto al beneficio de las generaciones futuras" (Caso relativo a la Delimitación Marítima en el área entre Groenlandia y Jan Mayen (Dinamarca c/ Noruega), 1993, C.I.J. 38, cit. en Brown, 1999:28).

En pronunciamientos sucesivos, se afianza esta incipiente línea jurisprudencial. Así, en el caso de las pruebas nucleares de Francia en el Pacífico Sur, que fue objeto de demanda por parte de Nueva Zelanda, la C.I.J. declinó su jurisdicción por tratarse de pruebas subterráneas en lugar de atmosféricas.

Sin embargo, el juez Weeramantry manifestó en voto particular su convicción de que la Corte tenía la obligación de tutelar los derechos de las generaciones futuras, arguyendo expresamente que "Esta Corte debe considerarse fiduciaria de los derechos de esas futuras generaciones de la misma manera que un tribunal doméstico actúa como fiduciario de los derechos de un niño incapaz de valerse por sí mismo. El reclamo de Nueva Zelanda en cuanto a que sus derechos se ven afectados no se relaciona solamente con los derechos de las personas que existen actualmente; los derechos del pueblo de Nueva Zelanda incluyen también los derechos de las personas por nacer, a los que una nación tiene el derecho y, ciertamente, también el deber de proteger" (Caso de las Pruebas Nucleares de 1995, Nueva Zelanda c/ Francia, 1995, C.I.J., 288; cit. en Brown, 1999: 28-29).

Y a propósito de la amenaza del uso de armas nucleares, la Corte aludió implícitamente a la quiebra del paradigma espacio-temporal, al estimar, en opinión consultiva, que "el poder destructivo de las armas nucleares no puede ser contenido ni en el tiempo ni en el espacio. Ellas 
tienen el poder de destruir toda la civilización y la totalidad del ecosistema del planeta".

Más adelante, la Corte dilucida la relevancia jurídica de la cuestión al estimar que el derecho de las generaciones futuras es merecedor de una tutela jurídica adecuada: "...[a] fin de aplicar correctamente al presente caso las normas de la Carta sobre el uso de la fuerza y el derecho aplicable en los conflictos armados, particularmente el Derecho humanitario, resulta imperativo para la Corte tomar en cuenta las caracteristicas únicas de las armas nucleares y en particular... su capacidad para perjudicar a las generaciones futuras" (Opinión Consultiva sobre la legalidad de la amenaza o uso de las armas nucleares, C.I.J., 1996, cit. por Brown, 1999: 29).

Más recientemente, el Institut de Droit International se ha pronunciado sobre la necesidad de incorporar elementos de una equidad intergeneracional al discurso jurídico, al proclamar, en una resolución sobre responsabilidad por daño ambiental, que "el derecho ambiental internacional está desarrollando importantes nuevos lazos con el concepto de la equidad intergeneracional... (que)...están influyendo en las cuestiones relativas a la responsabilidad" (Responsability and Liability under International Law for Environmental Damage, Institut de Droit
International, 4 de septiembre de 1997, cit. por Brown, 1999: 29).

En suma, la reconciliación del hombre con el medioambiente a través del Derecho requiere un esfuerzo por descomponer el sistema jurídico para buscar nuevos instrumentos de protección y de tutela. La nueva perspectiva de análisis exige situar los problemas en "el vector complejo que relaciona ecología, espacio, tiempo y Derecho en el contexto de la crisis ecológica como crisis civilizatoria" (Serrano, 1992: 15).

Debe quedar claro, sin embargo, que, pese a la incardinación de estas cuestiones en un nuevo paradigma temporal, su alcance afecta de lleno a la ordenación espacial del poder jurídico-político, en la medida en que los problemas medioambientales trascienden con frecuencia el reducido marco de las fronteras estatales.

Un tratamiento de estos problemas demanda una consideración global que permita adoptar soluciones efectivas al nivel supra e infraestatal. Es necesario, pues, pensar, simultáneamente, en una estrategia de centralización y descentralización que permita adecuar los espacios de validez y vigencia en función de la propia delimitación geográfica de los ecosistemas (Serrano, 1992: 15). 


\section{Un nuevo paradigma de los derechos} humanos

A la luz de ello, entiendo que la comprensión de los derechos humanos como categorías temporalmente vinculadas al presente cercena el estatuto de las libertades al vaciarlas de su valor proyectivo. Es cierto que la Modernidad inauguró una concepción del tiempo como tiempo presente. $Y$ es cierto también que, en consecuencia, el Derecho moderno excluyó del ámbito de la juridicidad, por regla general, los hechos, actos o acontecimientos que no se hubieran actualizado en la realidad social. La aplicación de una norma requería entonces la plena materialización social del supuesto de hecho. Y la titularidad de los derechos no quedó al margen de esta comprensión moderna de la temporalidad, por lo que, salvo muy contadas excepciones, la imputación de derechos y deberes requería una existencia individual y concreta.

Frente a la crisis del paradigma espacio-temporal de los derechos humanos, férreamente vinculado al espacio geográfico del Estado-nación y a la dimensión temporal del presente, reivindicamos un nuevo paradigma espacio-temporal (de Julios-Campuzano, 2003: 118) construido sobre una comprensión global de los derechos humanos y sobre su apertura hacia el futuro, mediante la protección de intereses difusos de titularidad colectiva que deben ser adecuadamente protegidos. Esos intereses difusos, como sostiene Reich, tienen el carácter de bienes públicos y atañen a la calidad de vida global (Reich, 1988: 111).

En este contexto, justamente, la categoría de derecho subjetivo, en cuanto elaboración conceptual de la dogmática individualista burguesa, resulta abiertamente inadecuada en la medida en que propicia la identificación de los derechos fundamentales y los derechos patrimoniales, acentuándose el énfasis apropiatorio que implica las ideas de exclusividad, de singularidad y de disponibilidad. Frente a ese concepto, de honda raigambre formalista y larga tradición en la dogmática jurídica positivista, es necesario reafirmar el carácter inclusivo, universal e indisponible de los derechos, escindiendo el nexo entre derechos fundamentales y derechos subjetivos (Ferrajoli, 2011b: 15$)^{9}$.

No huelga soslayar, como ha significado Serrano al referirse al estatuto jurídico de los derechos medioambientales, que la categoría de derecho subjetivo está hondamente marcada por la apropiación capitalista en términos excluyentes, como fundamento del orden capitalista y

\footnotetext{
${ }^{9}$ En este sentido, el jurista italiano agrega que esa diferenciación tiene su origen en la diversa ascendencia teórica de las dos categorías de derechos: mientras los derechos fundamentales remiten a la filosofía iusnaturalista y contractualista de los siglos XVII y XVIII, los derechos patrimoniales se remontan a la tradición civilista y romanista.
} 
arquetipo de los derechos de propiedad: "Esto es justo lo contrario de lo que necesitamos para proteger recursos naturales que en nuestro sistema de mercado son bienes comunes, de libre disposición, difusos y gratuitos" (Serrano, 1992: 115).

Al postular un nuevo paradigma de los derechos humanos apostamos, por tanto, por la superación de las visiones localistas, pacatas y alicortas, territorialmente ancladas en los límites territoriales del Estado; rechazamos, simultáneamente, la concepción individualista de los derechos y de los bienes jurídicos con su marchamo excluyente y apropiatorio, y postulamos, finalmente, la necesidad de una distribución equitativa de los derechos y de los bienes comunes que contemple una perspectiva intergeneracional.

Desde siempre, la imprevisibilidad de la propia existencia ha abocado al hombre a la incertidumbre sobre lo que le deparará el devenir. El ser humano ha luchado continuamente por reducir la incertidumbre y la inseguridad que el futuro comporta. Ahora, sin embargo, la inseguridad adquiere una nueva dimensión, dada la magnitud de las amenazas y la dificultad para hacer frente a los daños irreparables que se podrían derivar de su acaecimiento.

Esto otorga al Derecho una dimensión que la primera Modernidad no llegó a vislumbrar, una dimensión que incorpora al Derecho la perspectiva del daño potencial, del riesgo grave e irreparable, del peligro inminente, a cuya prevención deben consagrarse las instituciones y regulaciones jurídicas.

El Derecho se abre, así, al futuro, para trascender la perspectiva que implica la vieja idea de la causación del daño y superar la encrucijada de su propia insuficiencia: un Derecho precario que sólo actúa ex post factum para paliar daños que pueden resultar irreparables. La evaluación de riesgos se convierte entonces en la nueva forma de la imputación jurídica (Serrano, 2010: 196 ss.). Derecho y futuro quedan así indisociablemente unidos a través del riesgo.

La nueva dimensión global de riesgos de alcance planetario, la crisis del principio de soberanía y la consiguiente insuficiencia del modelo estatal para gestionar y prevenir adecuadamente los riesgos que se ciernen sobre la humanidad, ponen de manifiesto la perentoriedad de implementar modelos de gobernanza transnacional que incorporen una óptica cosmopolita (Held, 2012: 142).

En efecto, los problemas globales precisan de la articulación de respuestas eficaces, solidarias y justas en términos sociales. De ahí se infiere la necesidad de avanzar en la progresiva implantación de estructuras y mecanismos transnacionales de gestión, avalados por 
procedimientos democráticos de decisión, ante la constatación de la precariedad de los instrumentos institucionales de los que disponemos. Esta necesidad se refuerza cuando vislumbramos que el apremio de nuestro tiempo nos aboca hacia la evidencia de que la política y el Derecho deben proteger efectivamente no sólo a las generaciones actuales sino a las venideras (de JuliosCampuzano, 2003: 157 ss.; Held, 2012), lo cual conduce a la vía del constitucionalismo cosmopolita, que ha tenido estimulantes desarrollos teóricos y que se manifiesta, también, en un proceso de constitucionalización del derecho internacional, en la expansión progresiva del catálogo del derecho humanos, en el diálogo entre cortes y en la trasposición de los principios constitucionales por vía jurisprudencial y en la gestación de un derecho constitucional común que, en el ámbito supranacional, incide directamente sobre los procesos constituyentes locales (Klabbers, Peters, Ulfstein, 2011; Halmai, 2014: 6-7).

Ello nos abre, en opinión de Ferrajoli, un nuevo horizonte para el constitucionalismo y el garantismo, al proyectar el paradigma constitucional hacia el futuro, para concebirlo como un modelo a largo plazo, además de global, que se sustancia: a) en un constitucionalismo de Derecho privado, capaz de establecer reglas y vínculos para los poderes económicos privados;

b) en un constitucionalismo de Derecho internacional, pues las agresiones al medio ambiente alcanzan dimensiones globales y precisan ser combatidas en el escenario internacional, introduciendo normas, límites, vínculos, controles, funciones e instituciones de garantía a nivel planetario;

c) por último, es necesario afrontar el problema energético que amenaza con colapsar la economía del planeta apostando por las energías limpias. Ese garantismo global de los bienes fundamentales requiere el desarrollo de una esfera pública planetaria y la creación de una política global, basada en la cooperación mundial y garante de un interés público general (Ferrajoli, 2011b: 70-73) ${ }^{10}$.

La construcción de ese nuevo paradigma es, en virtud de lo expuesto, una demanda inaplazable a la que la doctrina habrá de ir dando respuesta en años venideros. Se trata de comprender que los derechos no son apropiaciones "espaciotemporales", sino que representan una suerte de catálogo ético sobre el cual transformar el

\footnotetext{
${ }^{10}$ Conviene tener en cuenta, sin embargo, las admoniciones del profesor Pérez Luño sobre el optimismo desmedido en la incorporación de garantías ambientales en los textos constitucionales. El constitucionalismo ambiental y el derecho ecológico pueden resultar, a la postre, un espejismo, al inducir una confusión entre la realidad y el deseo (Pérez Luño, 2012: 57-62).
} 
presente y cimentar un futuro más esperanzador, que no puede descansar sobre la exclusión ni sobre el uso indiscriminado e irresponsable de los recursos naturales.

Conviene precisar que este nuevo paradigma espacio-temporal de los derechos humanos no prescinde de su concreta incardinación histórica ni puede contemplarse como una estrategia de desplazamiento de los viejos derechos de titularidad individual; antes bien, este nuevo paradigma es plenamente fiel a las conquistas históricas de los derechos humanos y a su configuración generacional, pero trata de superar la vieja concepción formalista de los derechos humanos -heredera de la concepción del positivismo legalista- que los reducía a su comprensión en términos individualistas y erigir, progresivamente, a los derechos humanos como el catálogo ético de la nueva era global. La humanización del Derecho reclama la capacidad expansiva de los derechos humanos más allá de las fronteras territoriales y del tiempo presente (de Julios-Campuzano, 2011).

Es obligado notar que el nuevo paradigma espacio-temporal representa, en consecuencia, un paso decisivo en la reconciliación de los derechos humanos con el legado de la Modernidad y con la exigencia de universalidad de los mismos que es elemento constitutivo y definitorio de los derechos humanos (Carrillo-Salcedo, 2000: 41); una especie de segunda Modernidad en la que ésta quedaría simultáneamente superada y purificada de sus contaminaciones teóricas, en la línea de la propuesta de Habermas que aboga por la plena realización del proyecto moderno (Habermas, 1998, 98). Se trata, en suma, de una apuesta por la conciliación entre Modernidad y modernización, entre Derecho y justicia, entre globalización y universalización de los derechos humanos, cifrada en dos tesis principales:

$1^{\mathrm{a}}$. Los derechos humanos de los ciudadanos no pueden realizarse a costa de los derechos humanos de los infraciudadanos: la teoría de los derechos humanos debe salir del impasse teórico de su encuadre estatal-nacional que lo enmarca férreamente en el ámbito de los ordenamientos estatales. Un nuevo paradigma de los derechos humanos debe superar las angostas limitaciones geográficas en aras de una comprensión global de los derechos en el completo marco espacial de un mundo interdependiente.

El Estado ya no es un instrumento institucional suficiente para dar respuesta a problemas fundamentales de amplitud planetaria. Existe una conciencia, cada vez más sólidamente arraigada, de la dimensión planetaria de la emancipación, "la conciencia de que la humanidad no es un puro mosaico de Estados igualmente soberanos, sino más bien una comunidad de personas y de pueblos que están enfrentados a fenómenos 
múltiples de dominación individual y colectiva" (Pureza, 1996: 123).

Se trata, entonces, de abandonar el espacio internacional como campo de batalla en el que los intereses económicos dirimirán el grado de satisfacción de los derechos, como si éstos pudieran ser objeto de apropiación sin ser estragados. Los derechos no pueden ser el fruto de las conquistas mercantiles en el ring de la economía. La fuerza normativa de los derechos no puede quedar supeditada a una victoria trucada, que condena a la miseria a tres cuartas partes de la población mundial.

La globalización plantea así un desafío que no podemos eludir: seguir entendiendo los derechos humanos como subproductos político-culturales objeto de apropiación o, por el contrario, abandonar los esquemas de una realización parcial y fragmentaria, condensada en el modelo estatal-nacional, para dar paso a una concepción omnicomprensiva de los derechos humanos que contemple los problemas en su radical complejidad, como algo que concierne a la humanidad toda.

$2^{\mathrm{a}}$. En segundo lugar, los derechos humanos de la generación presente no pueden realizarse a costa de los derechos humanos de las generaciones futuras: se hace preciso superar el marco temporal de referencia de los derechos humanos como categorías jurídicas sumergidas de lleno en el presente.

Esta concepción moderna de la temporalidad ha sido malévolamente utilizada, en tiempos recientes, para dar fundamento a una concepción truncada de los derechos humanos como principios legitimadores del statu quo vigente y como estrategias puramente instrumentales de pacificación social. La recuperación de la doble dimensión emancipatoria y utópica de los derechos humanos exige la incorporación de ambas en una dimensión proyectiva. Derechos que son de todos y que a todos alcanzan.

Por eso, deben materializarse históricamente en la experiencia concreta de los hombres, emancipándolos de las circunstancias que constriñen su pleno desarrollo como personas y que atacan a su dignidad; pero, al mismo tiempo, esa concreción en el presente no puede sacrificar las expectativas de una realización cada vez más completa de estos derechos en el futuro.

En la era de la globalización, el progreso moral de la humanidad ha quedado ya indisociablemente unido a la creación de las condiciones que permitan el disfrute efectivo de los derechos: la superación de una concepción periclitada de los derechos humanos trae a colación el desafío ineludible de su universalización. 
La incorporación de un nuevo paradigma espacio-temporal de los derechos humanos es un aldabonazo a ese imperativo ético que se hace sentir cada vez con más fuerza y del que cada vez resultará más difícil escapar. En nuestra era se está produciendo una mutación profunda de nuestra percepción del mundo y de la ordenación de las relaciones sociales, económicas y políticas. Esta situación hace cada vez más evidente la existencia precaria de los derechos humanos. $\mathrm{Su}$ existencia no se mide, precisamente, por el grado de eficacia y de respeto, sino por la insuficiencia jurídica e institucional para hacerlos efectivos.

De ahí se deriva que la existencia de los derechos es puesta en cuestión, de continuo, ante la alarmante cantidad de violaciones flagrantes que se producen en todos los rincones del planeta. Por eso, esa sensación de precariedad está alimentando una demanda creciente de eficacia que se siente cada vez con más fuerza y que adquiere tantas veces tintes dramáticos. La globalización hace cada vez más evidente la contradicción entre el progreso técnicoeconómico y el progreso moral, entre la modernización capitalista y la Modernidad filosófico-cultural, entre la racionalidad de los medios y la de los fines, entre la expansión vertiginosa del capital y la realización de los derechos humanos.
La sociedad del riesgo reclama, así, una nueva forma de comprender el Derecho y una perspectiva más amplia y compleja de la realización de los derechos humanos: aquella que concierne a la humanidad toda, sensible a la interdependencia, refractario a ficticias compartimentaciones geográficas, en una era de crisis del viejo paradigma westfaliano del Derecho; un Derecho que requiere, hoy, anticipar el mañana, para disipar incertidumbres, para gestionar, racionalizar y administrar riesgos, y que apunta, por tanto, hacia la prevención.

El nuevo paradigma de los derechos humanos se construye sobre la crisis irreversible del principio de soberanía y sobre la incapacidad de los Estados para gestionar problemas de magnitud planetaria, y descansa, asimismo, sobre una concepción vertical de la justicia, entendida como justicia intergeneracional.

Justamente, por ello, la efectiva realización de los derechos humanos en la era de la globalización requiere la superación de un paradigma espaciotemporal, cuyo agotamiento resulta incontestable, y su sustitución por un nueva comprensión de los derechos humanos, en aras de la ampliación del horizonte de los derechos a todos los seres humanos y de la salvaguarda del planeta para las generaciones futuras. 
BIBLIOGRAFÍA:

- ANAND, R.; International Environmental Justice. A North-South Dimension,London, Routledge, 2016.

- ARRIBAS HERGUEDAS, F.; "Sostenibilidad ecológica, justicia intergeneracional y democracia liberal" en Actas de la XVI semana de Ética y Filosofía Política, Murcia, Universidad de Murcia, 2009.

- BARRANCO AVILÉS, M Ma.C.; “Constitución, Derechos Humanos y Filosofía del Derecho: una teoría de la justicia para el constitucionalismo contemporáneo", Anuario de Filosofía del Derecho, 2009, pp. 13-31.

- BAUMAN, Z.; Globalizaçao. As consequências humanas, Rio de Janeiro, Zahar, 1999.

- BAUMAN, Z.; La sociedad individualizada, Madrid, Cátedra, 2001.

- BAUMAN, Z.; Modernidad líquida, México, F.C.E., 2002.

- BECK, U.; "La reinvención de la política: hacia una teoría de la modernización reflexiva", en Beck, U., Giddens, A. y Lash, S., Modernización reflexiva. Politica, tradición y estética en el orden social moderno, Madrid, Alianza, 1997.

- BECK, U.; ¿Qué es la globalización? Falacias del globalismo, respuestas a la globalización, Barcelona, Paidós, 1998.

- BECK, U.; Un nuevo mundo feliz, Barcelona, Paidós, 2001.

- BECK, U.; La sociedad del riesgo mundial. En busca de la seguridad perdida. Barcelona, Paidós, 2008 .
- BELL, D.; El advenimiento de la sociedad postindustrial: un intento de prognosis social, Madrid, Alianza, 2006.

- BELLOSO MARTÍN, N.; “Algunos efectos perversos de la globalización: las empresas transnacionales y el deber de respeto de los estándares mínimos internacionales de derechos humanos", Cuadernos Electrónicos de Filosofía del Derecho, 28, 2013.

- BOLZÁN DE MORAIS, J.L.; As crises do Estado e da Constituiçao e a transformaçao espaço-temporal dos Direitos humanos, Porto Alegre, Livraria do Advogado, 2011.

- BROWN WEISS, E.; Un Mundo Justo para las Futuras Generaciones. Derecho Internacional, Patrimonio Común y Equidad Intergeneracional, Madrid, Mundi-Prensa, 1999.

- CAPELlA, J.R.; "Estado y Derecho ante la mundialización: aspectos y problemáticas generales", en Transformaciones del derecho en la mundialización, Madrid, Consejo General del Poder Judicial, 2000.

- CLIMENT SANJUÁN, V.; "Sociedad del riesgo. Producción y sostenibilidad", Papers. Revista de sociología, 82, 2006, pp. 121-140.

- CARRILLO-SALCEDO, J.A.; "El problema de la universalidad de los derechos humanos en un mundo único y diverso", en Derechos culturales y derechos humanos de los inmigrantes, Madrid, Universidad Pontificia de Comillas, 2000.

- CRUTZEN, P.J.; "Geology of mankind", Nature, 415, 2002, p. 23.

- DE CÓZAR ESCALANTE, J.M.; "Principio de precaución y medio ambiente", Revista Española de Salud Pública, v. 79, no. 2, marzo-abril 2005, pp.133-144. 
- DE JULIOS-CAMPUZANO, A.; En las encrucijadas de la Modernidad. Política, Derecho y Justicia, Sevilla, Universidad de Sevilla, 2000.

- DE JULIOS-CAMPUZANO, A.; La globalización ilustrada. Ciudadanía, derechos humanos y constitucionalismo, Madrid, Dykinson - Instituto de Derechos Humanos Bartolomé de las Casas, 2003.

- DE JULIOS-CAMPUZANO, A.; "La ética global de los derechos humanos. Una aproximación prospectiva al impacto de las nuevas tecnologías", Cuadernos Electrónicos de Filosofía del Derecho, 22, 2011.

- DENNINGER, E.; "Racionalidad tecnológica, responsabilidad ética y derecho posmoderno", en Derechos humanos y Constitucionalismo ante el tercer milenio, Madrid, Marcial Pons, 1996.

- FARIA, J.E.; $O$ Direito na economia globalizada, Sao Paulo, Malheiros, 2000.

- FARIA, J.E.; Direito e Cojuntura. Sao Paulo: Saraiva - Fundaçao Getulio Vargas, 2008.

- FERRAJOLI, L.; "Más allá de la soberanía y la ciudadanía: un constitucionalismo global", en Teoría de la Constitución. Ensayos escogidos, México, UNAM-Porrúa, 2005, pp. 397-409.

- FERRAJOLI, L.; Poderes salvajes. La crisis de la democracia constitucional, Madrid, Trotta, 2011a.

- FERRAJOLI, L.; Por uma teoria dos direitos e dos bems fundamentais, Porto Alegre, Livraria do Advogado, 2011b.

- GIDDENS, A.; Un mundo desbocado. Los efectos de la globalización en nuestras vidas, Madrid, Taurus, 2000.
- GROSSERIES, A.; "Teorías de la justicia intergeneracional: una sinopsis", Revista Jurídica de la Universidad Autónoma de Madrid, 32, 2000, pp. 217-237.

- HABERMAS, J.; "Modernidad versus postmodernidad", en Picó, J. (comp.), Modernidad y Postmodernidad, Madrid, Alianza, 1998, pp. 87-102.

- HALMAI, G., Perspectives on global constitutionalism. The use of foreign and international law, La Haya, Eleven, 2014.

- HANSCHEL, D.; "Progress and the Precautionary Principle in Administrative Law Country Report on Germany", en Recent Trends in German and European Constitutional Law, Berlin, Springer Berlín, 2006, p. 179-209.

- HELD, D.; Cosmopolitismo. Ideales y realidades, Madrid, Alianza, 2012.

- IANNI, O.; A era do globalismo, Rio de Janeiro, Civilizaçao Brasileira,1999a.

- IANNI, O.; "A política mudou de lugar", en Desafios da globalizaçao, $2^{\mathrm{a}}$ edic., Petrópolis, Vozes, 1999b.

- IGLESIAS VILA, M.; “¿Los derechos humanos como derechos especiales? Algunas ventajas de una concepción cooperativa de los derechos humanos", Anuario de Filosofia del Derecho, 2016, pp. 119-144.

- JONAS, H.; El principio de responsabilidad. Ensayo de una ética para la civilización tecnológica, Barcelona, Herder, 1995.

- KLABBERS, J., PETERS, A., ULFSTEIN, G.; The Constitutionalization of International Law, Oxford, Oxford University Press, 2011. 
- LEMA AÑÓN, C.; "La reciprocidad indirecta y las generaciones futuras", Anuario de Filosofía del Derecho, 2015, pp. 203-226.

- MERCADO PACHECO, P.; "Libertades económicas y derechos fundamentales. La libertad de empresa en el ordenamiento multinivel europeo", Cuadernos Electrónicos de Filosofía del Derecho, 26, 2012a. pp. 341-372.

- MERCADO PACHECO, P.; "Desarrollo sostenible y gobernanza: retóricas del derecho global y de la justicia ambiental", en Derecho, globalización, riesgo y medio ambiente, Valencia, Tirant Lo Blanch, 2012b. pp. 93-117.

- O'BRIEN, R.; Global Financial Integration: The End of Geography, London, Chatham House/Pinter, 1992.

- PÉREZ LUÑO, A.E.; Perspetivas e tendências atuais do Estado Constitucional, Porto Alegre, Livraria do Advogado, 2012.

- PÉREZ LUÑO, A.E.; "Nuevo derecho, nuevos derechos", Anuario de Filosofía del Derecho, 2016, pp. 15-36.

- PUREZA, J.M.; “¿Derecho cosmopolita o uniformador? Derechos humanos, Estado de Derecho y Democracia en la posguerra fría", en Derechos humanos y constitucionalismo ante el tercer milenio, Madrid, Marcial Pons, 1996.

- REICH, N.; "Formas de socialización en la economía: reflexiones sobre el postmodernismo en la teoría jurídica", en Derecho y economía en el Estado social, Madrid, Tecnos, 1988.

- RUIZ SANZ, M.; “A la búsqueda de un paradigma jurídico ambiental", Cuadernos Electrónicos de Filosofía del Derecho, 25, 2012.
- SERRANO MORENO, J.L., Ecología y Derecho: Principios de Derecho Ambiental y Ecología Jurídica, Granada, Comares, 1992.

- SERRANO MORENO, J.L., "La sociedad del riesgo y el derecho de la sociedad", Cuadernos Electrónicos de Filosofía del Derecho, 21, 2010, pp. 184-201.

- SHAWCROSS, W., Le Village Planétaire, Paris, Stock, 1993.

- SNYDER, F.; Global Economics Networks and Global Legal Pluralism, EUI Working Papers, 99/6, Firenze, European University Institute, 1999.

- STRECK, L.; "Las transformaciones del derecho: clasicismo y contemporaneidad", Anuario de Filosofia del Derecho, 2016, pp. 3752.

- TURÉGANO MANSILLA, I.; Justicia global: los límites del constitucionalismo, Lima, Palestra, 2010.

- VIRILIO, P.; “Un monde superexposé: fin de l'histoire, ou fin de la géographie?", Le Monde Diplomatique, agosto 1997, p. 17.

- WALlERSTEIN, I.; The Capitalist WorldEconomy, Cambridge, Cambridge University Press, 1979.

- WALLERSTEIN, I.; Geopolitics and Geoculture, Cambridge, Cambridge University Press, 1991.

- WARAT, L. A., ¿Por quién cantan las sirenas? Informe sobre eco-ciudadanía, género y derecho incidencias del barroco en el pensamiento jurídico-, Florianópolis, UFSC, 1996. 
- WOLKMER, A.C.; VERAS NETO, F.Q. y caminhos da contemporâneidade, Sao Paulo, LIXA, I.M.; Pluralismo jurídico. Os novos Saraiva, 2010. 